- News \& Views •

\title{
Workshop on Dynamics, Transport and Chemistry of the UTLS Asian Monsoon
}

\author{
William J. RANDEL ${ }^{1}$, Laura L. PAN ${ }^{* 1}$, and Jianchun BIAN ${ }^{2}$ \\ ${ }^{1}$ National Center for Atmospheric Research, Boulder, Colorado, 80307-3000, USA \\ ${ }^{2}$ Key Laboratory of Middle Atmosphere and Global Environment Observation, Institute of Atmospheric Physics, Chinese Academy of \\ Sciences, Beijing 100029, China
}

Citation: Randel, W. J., L. L. Pan, and J. C. Bian, 2016: Workshop on dynamics, transport and chemistry of the UTLS Asian Monsoon. Adv. Atmos. Sci., 33(9), 1096-1098, doi: 10.1007/s00376-016-6169-9.

\section{Overview}

The upper troposphere-lower stratosphere (UTLS) of the Asian summer monsoon (ASM) region is characterized by a continental-scale anticyclonic circulation, which is dynamically active and coupled to monsoonal convection. The monsoon anticyclone exhibits anomalous chemical and aerosol characteristics, linked to the outflow of deep convection and the large-scale circulation, and strongly influences the global UTLS composition during boreal summer. Ongoing increases in regional surface emissions enhance current scientific interests. There is substantial work in the research community aimed at improved understanding of the behavior of the UTLS monsoon region using observations and mod- els. Key topics that are poorly understood include dynamical and chemical coupling with convection, three-dimensional transport pathways from the surface to the stratosphere, composition/reactive chemistry in the monsoon region, and microphysics and the tropopause aerosol layer. There are also plans for aircraft-based field experiments and enhanced insitu sampling in the near future, which promise novel data to address these questions. To summarize current understanding and plan for future activities, a workshop was held March 7-11 at Boulder, Colorado, focused on Dynamics, Transport and Chemistry in the UTLS Asian Monsoon. The workshop was aimed at synthesis of observations from satellites, aircraft and balloons, modeling from regional to global scales, and developing key questions for the focus of future research.

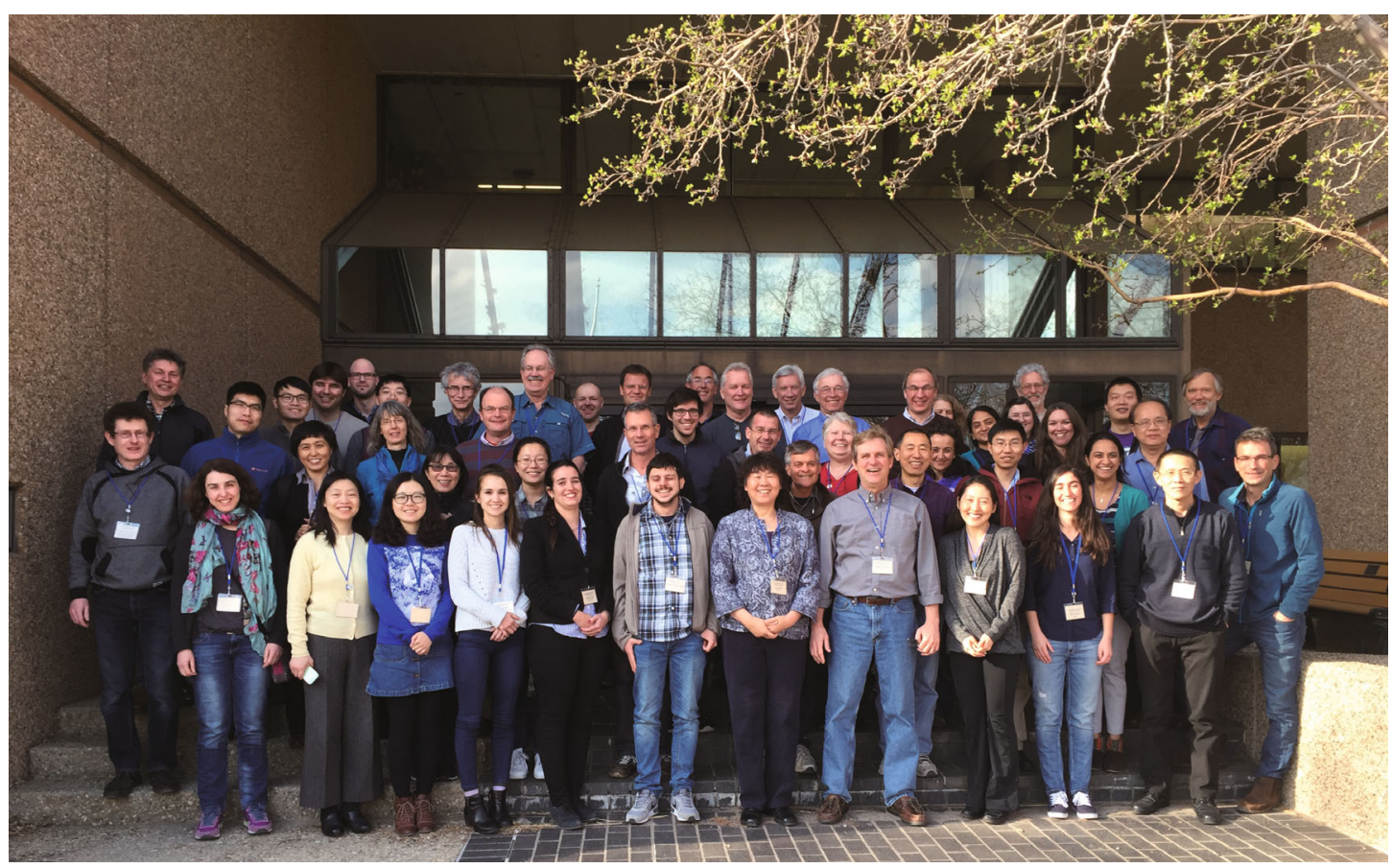

Fig. 1. Workshop group photo.

\footnotetext{
* Corresponding author: Laura L. PAN

Email: liwen@ucar.edu
} 
The workshop was attended by $\sim 50$ scientists and students who are actively engaged in UTLS monsoon research (Fig. 1). The summary here is a brief overview of the key topics and discussions; a list of workshop participants and the individual presentations made at the workshop can be found here: https://www2.acom.ucar.edu/asian-monsoon.

\section{Dynamics}

The ASM system plays a dominant role in large-scale climate variability influencing over half of the world's population. Monsoon related droughts and floods, and effects of enhanced aerosols and poor air quality are serious environmental hazards. The monsoon circulation and water cycle are driven by atmospheric heating tied to convection, with complex behavior across a wide range of space-time scales. New research is recognizing the importance of the UTLS as an integral component of the monsoon system.

\subsection{Monsoon dynamics and aerosol interactions}

One aspect of monsoonal behavior emphasized over recent decades regards the feedback effects of atmospheric aerosols, especially absorbing aerosols (black carbon), which regulate and interact with heat sources and influence circulation and water cycles. Deep convection and aerosol feedbacks are strongly coupled with circulations extending to the UTLS, and new work focuses on quantifying dynamical and radiative feedbacks and coupling with lower altitudes. Improved understanding of the UTLS region and its impact on dynamical, chemical and radiative behavior at lower levels is a major research goal. (Contribution from Bill LAU)

\subsection{Anticyclone behavior, stratosphere-troposphere ex- change (STE), and the tropopause}

The UTLS monsoon anticyclone is an inherently unstable circulation, with sub-seasonal modulation of the anticyclone center and "eddy shedding" as key aspects of observed variability (in both dynamics and constituents). Discussions at the Workshop focused on understanding bimodality of the anticyclone (with centers over Tibet and Iran), and quantifying the relationships between shifting of the anticyclone, large-scale precipitation and convection, and Rossby wave dynamics. El Niño / Southern Oscillation (ENSO) influences interannual variability, although interactions are complex. Further work aims at evaluating STE and behavior of the tropopause linked to monsoon dynamics. (Contributions from Yimin LIU, Chiara CAGNAZZO, Mathias NUETZEL, Rongcai REN, Yutian WU and Pengfei ZHANG)

\section{Transport}

Transport associated with the ASM anticyclone was the most discussed topic during the workshop. Using different approaches and tools, the participants addressed and explored the following issues and questions:

\subsection{Anticyclone transport boundaries and pathways from the boundary layer}

To quantify transport and confinement within the anticyclone, it is important to identify its boundaries. Discussions included the use of geopotential height, stream function, jet structure and isentropic PV gradient to identify the edge of the anticyclone. Analyses of the thermal tropopause and cold point show that the ASM tropopause is higher than the equatorial tropopause during this season. Quantifying preferred transport pathways from the boundary layer to the UTLS anticyclone is important for understanding driving processes and identifying dominant source regions. Various approaches show that the southern flank of the Tibetan Plateau is a key region for boundary layer air to enter the anticyclone. The pathways and time scales for air in the anticyclone to enter the stratosphere are topics of active research.

\subsection{Influence of convection on the UTLS}

Calculations estimating the influence of deep convection on the UTLS can be made using backward or forward trajectories coupled with (diurnally resolved) brightness temperatures from geostationary satellites (as a proxy for deep convection). Preferred source regions for the monsoon are the chronic deep convective regions over the South China Sea and Bay of Bengal. Global calculations of "convective influence" demonstrate that most of the tropical upper troposphere has intersected convection within the previous $\sim 2-5$ days.

\subsection{Transport and mixing tied to monsoon circulations}

The global behavior of UTLS mixing during boreal summer was discussed based on various mixing diagnostics. The ASM anticyclonic flow plays a key role for mixing of higher latitude lower stratospheric air into the low latitude tropical tropopause layer (TTL), influencing the seasonal cycle, and may also contribute to cross-equatorial transport. Transport through the anticyclone may be evaluated using tracers and diagnostics based on meteorological analyses (such as identifying manifolds or Lagrangian Coherent Structures).

The analyses presented involve Lagrangian models (Ken BOWMAN, Bernard LEGRAS, John BERGMAN, Paul KONOPKA, Rolf MÜLLER, and Baerbel VOGEL), chemical transport and chemistry-climate models (Suvarna FADNAVIS, Laura PAN), diagnostics from dynamical fields and idealized tracers (Marta ABALOS, Clara ORBE) and studies combining trajectory model calculations and observations (Brice BARRET, Klaus GOTTSCHALDT, Mike FROMM and Nathaniel LIVESEY).

\section{Composition and Chemistry}

\subsection{Large-scale behavior of chemical composition from satellite observations}

The ASM impact on UTLS composition has been documented by satellite measurements, especially from the decade-long records from limb-sounding instruments MLS, 
MIPAS and ACE-FTS. These data sets reveal strong signatures of enhanced boundary layer tracers within the anticyclone. The observations also show synoptic-scale variability in numerous species with stratospheric or tropospheric origins. The combination of species provides a fingerprint of source regions for the UTLS. Observations of pollution tracers (such as CO from MLS or PAN from MIPAS) demonstrate transport and eddy shedding events tied to dynamical circulations. (Contributions from Michelle SANTEE, Gabi STILLER, Mijeong PARK, Federico FIERLI, Suvarna FADNAVIS and Jiali LUO)

\subsection{In situ observations from aircraft and balloons}

Limited in-situ measurements from in-service aircraft have provided detailed composition measurements, including short-lived hydrocarbon species that demonstrate rapid transport (a few days) from the boundary layer to the upper troposphere (10-12 km). However, the lack of such measurements above $\sim 12 \mathrm{~km}$ limits the understanding of transport to higher altitudes. There are limited measurements of reactive nitrogen in the monsoon UTLS, and poor understanding of the contributions of near-surface emissions versus lightning generation. Campaign-based balloon measurements of water vapor, ozone, aerosol and cirrus information (from COBALD instrument backscattering measurements) have been made in the monsoon region over China since 2009, more recently including particle counter measurements. A similar measurement campaign was conducted from 5 launch sites in India last year. While limited in sampling, these provide novel ground-truth evaluation of satellite measurements, quantitative estimates of supersaturation and cloud microphysical processes and aerosol behavior. (Contributions from Angela BAKER, Jianchun BIAN, Jean Paul VERNIER, and Shradda DHUNGEL)

\subsection{Impacts on stratospheric water vapor}

The Asian and North American monsoon regions are characterized by enhanced water vapor in the lower stratosphere and frequent occurrence of cirrus near the tropopause. Observational and modeling studies are aimed at understanding the contribution of large-scale circulation vs. extreme deep convection in maintaining these patterns. Trajectory studies based on meteorological reanalyses, incorporating convective influence, are able to capture the broad-scale water vapor and cirrus behavior. Temporal variations in lower stratospheric water vapor are closely tied to temperatures and dehydration on the equatorward (cold) side of the anticyclone. However, extremely moist air in the lower stratosphere is observed (infrequently) in satellite measurements (and field campaigns), demonstrating the direct influence of extreme convection. The relative influence of large- vs. small-scale processes on UTLS water vapor and clouds is an outstanding research topic. (Contributions from Michael SCHWARTZ, Rei UEYAMA, Wuke WANG and Bill RANDEL)

\subsection{Aerosols and Clouds in ASM region}

The Asian Tropopause Aerosol Layer (ATAL) was discovered based on satellite lidar measurements. It is an annu- ally occurring feature that may be strengthening over time as a result of growing Asian pollution. Several balloonbased measurement campaigns have made direct measurements of the ATAL, with results showing reasonable agreement with satellite-derived observations. Recent measurements, including aerosol backscatter and particle size distribution measurements, suggest that the ATAL may be primarily composed of sulphate aerosols. Global aerosol modeling studies (incorporating climatological surface precursor emissions) show reasonable agreement with satellite and in-situ measured aerosol behavior, and suggest a modest radiative impact for the ATAL. (Contributions by Jean Paul VERNIER, Terry DESHLER, Jianchun BIAN, Simone BRUNAMONTI, Teresa JORGE, Ru-Shan GAO, Pengfei YU and Mian CHIN)

\section{Outstanding questions}

The last half day of the Workshop was aimed at discussions on outstanding questions, and strategies for future measurements and modeling activities. Some of the key questions include:

1) How will the monsoons (including the UTLS circulation) evolve in a changing climate? What are the impacts of increasing pollution over SE Asia?

2) What controls the strong upward circulations in the monsoon? What are the specific influences of aerosols?

3 ) Is the monsoon anticyclone bimodal in location or intensity? If so, what are the links to convection, 3D circulation and transport?

4) What is the altitude profile of convective outflow in the monsoon regions? How can we best characterize the full spectrum of convection?

5) What are the relative roles of deep convection and large-scale circulation in pumping boundary layer air to the tropopause level? What is the time scale for air within the ASM anticyclone to enter the stratosphere?

6) What is the relationship and coupling between ASM 3D circulation and the monsoon Hadley cell, and with the stratospheric Brewer - Dobson circulation? What are the relationships between vertical and horizontal transport?

7) What reactive chemistry and aerosol growth processes are occurring in the UTLS? Is there an anthropogenic signal in the ATAL? Is the monsoon a pathway for transport of sulfur to the stratosphere?

The workshop discussions have provided an updated picture of the state of the science regarding ASM UTLS research. The discussions also provided useful input for the StratoClim group, which is making an active effort to target some of these questions in the upcoming airborne field campaign (campaign plan overviewed by Markus REX).

The workshop organizing committee include William J. RANDEL (NCAR, USA), Laura L. PAN (NCAR, USA), Jianchun BIAN (CAS/IAP, China), Chiarra CAGNAZZO (ISAC-CNR, Italy), Rolf MÜLLER (FZJ, Germany) and Michelle SANTEE (JPL, USA). This workshop is sponsored by SPARC as a part of the SPARC-IGAC joint activity Atmospheric Composition and the Asian Monsoon (ACAM). 